\title{
Development of Agility Test Construction: Validity and Reliability of Karate Agility Test Construction in Kata Category
}

\author{
Dewangga Yudhistira ${ }^{1, *}$, Siswantoyo ${ }^{1}$, Tomoliyus $^{1}$, Sumaryanti $^{1}$, Devi Tirtawirya ${ }^{1}$, Paryadi $^{2}$, \\ La Ode Adhi Virama ${ }^{1}$, Sinta Naviri ${ }^{1}$, Noralisa ${ }^{1}$ \\ ${ }^{1}$ Faculty of Sport Sciences, Yogyakarta State University, Yogyakarta, Indonesia \\ ${ }^{2}$ Faculty of Teacher Training and Education, Mulawarman University, Indonesia
}

Received March 7, 2021; Revised May 13, 2021; Accepted June 6, 2021

\section{Cite This Paper in the following Citation Styles}

(a): [1] Dewangga Yudhistira, Siswantoyo, Tomoliyus, Sumaryanti, Devi Tirtawirya, Paryadi, La Ode Adhi Virama, Sinta Naviri, Noralisa, "Development of Agility Test Construction: Validity and Reliability of Karate Agility Test Construction in Kata Category," International Journal of Human Movement and Sports Sciences, Vol. 9, No. 4, pp. 697 703, 2021. DOI: 10.13189/saj.2021.090413.

(b): Dewangga Yudhistira, Siswantoyo, Tomoliyus, Sumaryanti, Devi Tirtawirya, Paryadi, La Ode Adhi Virama, Sinta Naviri, Noralisa (2021). Development of Agility Test Construction: Validity and Reliability of Karate Agility Test Construction in Kata Category. International Journal of Human Movement and Sports Sciences, 9(4), 697 - 703. DOI: 10.13189/saj.2021.090413.

Copyright $\odot 2021$ by authors, all rights reserved. Authors agree that this article remains permanently open access under the terms of the Creative Commons Attribution License 4.0 International License

\begin{abstract}
Background: Kata is a series of moves competed in karate that require agility in its movements. Purpose: This research aimed to determine the validity and reliability of karate agility test in kata category. Method: This was a developmental research. The data were collected using the Delphi technique, involving 7 experts and test-retest. The participants were 20 karate aged at least 20 years old who have practiced karate for 6 years and have won regional competitions. This was to determine the test of empirical validity and reliability. The content validity was calculated using the Aiken formula, the empirical validity was calculated using Pearson Product Moment, while the reliability was calculated using the Cronbach Alpha. Results: The results showed that the karate agility test in kata category had high validity and reliability. The Aiken results were as follows: Item (1) size has fit the karate in kata category with a value of V 0.85 ; Item (2) distance between cones has fit with a value of V 0.80 ; Item (3) equipment has fit with a value of V 0.80 ; Item (4) number of test repetitions has fit with a value of V 0.80 ; Item (5) test procedure has fit with a value of $\mathrm{V} 0.80$; Item (6) safe instrument has fit with a value of V 0.85 ; Item (7) agility has fit with a value of V 0.85 ; Item (8) score taking has fit with a value of $\mathrm{V} 0.80$. The results of Pearson
\end{abstract}

product moment $\mathrm{r}$-table were 0.444 , r-count (test 1 ) was 0.927 , r-count (test 2) was 0.903 , significance was $0.000<$ 0.05 . Conclusion: It can be concluded that the agility test can be used to measure the karate agility in kata category.

Keywords Agility Test, Karate, Kata Category

\section{Introduction}

Agility is one of the important aspects in achievement sports, especially sports that require a rapid change of direction [1][2]. For years, agility can be defined as a rapid body movement by changing direction quickly, accurately without losing balance [3][4][5]. However, the current definition of agility has become more complex. Agility is now defined as ability to perform body movements rapidly with changes in speed or direction in response to an action[4][6][5]. This definition has three meanings, namely movement to execute, perception of stimulus, and response selection [4]. Agility is not only applied to game sports, but martial arts also require agility to perform attacks, defense and interact with match 
situations [2], one of those martial arts is karate.

Karate is a Japanese martial arts which is now competed in the olympics [7]. Karate has three important components to learn: kihon, kumite and kata [8][9]. Kihon is a basic movement, kumite is a fight, while kata is a series of moves or an imagery fighting movement [10][7]. Karate has the characteristics of fast and dominant movements performed with high intensity and utilizing the anaerobic energy system [11][12]. This can be explained that agility has a vital role to gain victory in a karate match [3]. Agility in game sports and karate is very different. In karate, the agility used is to step and change direction forward and backward after making punches and kicks quickly [3]. In order to determine the increase in the agility aspect, an agility test is needed. So far, based on a literature review, there are only general field-based agility tests such as the T-test, Illinois Agility Test, Edgren Side Step Test, Lane agility drill, shuttle run, zig-zag test, 505 agility test, hexagon, quadrant jump. test, 10 meter shuttle, quick feet test, 20 yard shuttle, side step test, agility cone drill, box drill, AFL agility test, arrowhead drill, 20 yard agility, shuttle cross pick-up, balsom agility run [5][13][14]. On the other hand, the aforementioned test is good to be used to determine the initial ability. This is in line with the literature which states that at this time, tests to measure agility in field-based sports are less relevant to the characteristics of movement in competitions. [15].

So far, there has been very little in-depth study related to tests developed specifically for karate in kata category which resemble movements in actual matches. This is in line with the literature which states that tests related to agility interventions carried out in the form of special competitions in individual sports are still not widely found [16].

Recently, a development of the karate agility test in the kumite category was discovered. However, in this study, the test was designed to have determined the movement and the testor only provided a stimulus at the beginning of the movement with a whistle sound. Then, the test only tested the validity of the content, and did not test the empirical validity and reliability. On the other hand, kumite and kata also have different move characteristics, so that test was only suitable for kuite athlete. Furthermore, there was a research on the agility of karate at the age of 5-11 years. That research aimed more at developing motor skills because in the test, there were still movements such as jumping, running and doing basic techniques. Therefore, it is necessary to develop a special test that has measured the validity and reliability. There are several types of validity, namely criterion validity, construct validity, and content validity. Content validity is used to refer to the extent to which the content of the measuring instrument is considered to be able to measure things that represent the entire material to be evaluated [17][18][19][20]. Meanwhile, construct validity indicates the extent to which the instrument reveals a construct to be measured, then reliability is the level of accuracy and accuracy of the measuring instrument of a measurement procedure [17]. This research aimed to test the validity and reliability of the karate agility test in kata category which have been designed by the authors.

\section{Materials and Methods}

This research used developmental method supported with qualitative and quantitative approaches in order to create an in-depth research [20][21][22]. The data collection was approved by the karate coach. The participants involved to test the empirical validity and reliability were karate athletes specializing in kata category who have the following criteria: male, 20 years old, 20 athletes, at least 6 years of practicing karate and have won the word at the regional level and in prime condition do not experience fatigue or pain. Prior to conducting the test, the athletes were given instructions on the test procedure to be performed. Validity evaluation of the agility test used empirical and content validities. Content validity has three steps: First, the authors collected relevant sources of research, and conducted a preliminary participatory observation study to develop a test, then evaluated the data obtained; Second, using the delphi technique [23][24], where the researchers met 7 experts directly to assess the contents of the instrument. The third step was analyzing the data obtained in the form of quantitative results from the assessment of 7 experts with a scale of 4 and qualitatively in the form of suggestions from 7 experts. The assessment of empirical validity and reliability consisted of two steps. The first step was conducting test-retest. The agility test instrument was tested on 20 athletes 2 times on different days. The second step was after obtaining data from 2 experiments, the empirical validity will be calculated, followed by calculation of the reliability. The data were analyzed using Aiken formula [25][26], where it was used to calculate the coefficient of content validity as a as a basis for the results of the assessment of several experts on an item to what extent the item represents the construct that has been measured. The data analysis technique for empirical validity used statistical calculations for the Pearson product moment test. Then, reliability was measured using Cronbach's alpha.

\section{Results}

Based on data collection by observing and reviewing several documents in the form of journal articles and relevant textbooks, the authors created a karate agility test construction in kata category as seen in the following figure. 


\subsection{Karate Agility Test Construction in Kata Category}

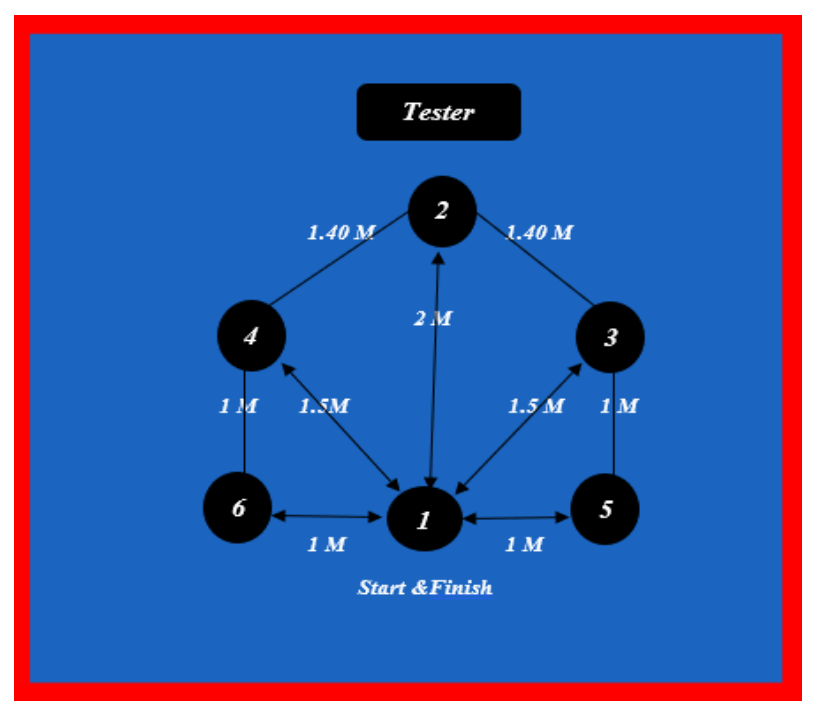

Image 1. Agility Test Construction

\section{Distance between cones for the test}

a. the distance between cone 1 and cone 2 is 2 meters

b. the distance between cone 1 and cone 3 is 1.5 meters

c. the distance between cone 1 and cone 4 is 1.5 meters

d. the distance between cone 1 and cone 5 is 1 meter

e. the distance between cone 1 and cone 6 is 1 meter

\section{Test equipments}
a. 1 stopwatch
b. 6 cones
c. 1 roll meter
d. karate mattress sized $8 \times 8$ meters

\section{Number of testors}

a. 1 testor prepares the equipment and measured the distance between the cones

b. 1 testor holds the whistle to stop the test when the athlete has finished the test

c. 1 testor holds the stopwatch

d. 1 testor gives instruction to stimulate movement

e. 1 testor observes and recorded the test results

\section{Test Procedure}

a) Cone 1 was the start position, the athlete stands with feet shoulder width apart and knees slightly bent facing cones 2

b) The athlete waits for the stimulus from the testor

c) The testor provides a sound stimulus in the form of numbers 2 to 6 randomly

d) When the testor provides a sound stimulus with sound 2 at the same time he turns on the stopwatch, the athlete steps forward towards cone 2. Arriving at cone 2 , the athlete performs maegeri kicks with the right foot. Then, the athlete steps back to cone 1 and gets ready to perform the movement instructed by testor e) When the testor provides a sound stimulus with sound 3 at the same time he turns on the stopwatch, the athlete steps forward towards cone 3. Arriving at cone 3 , the athlete performs gedanbarai block along with gyakutsuki punch and a stance with right foot at the front. Then, the athlete steps back to cone 1 and gets ready to perform the movement instructed by testor

f) When the testor provides a sound stimulus with sound 4 at the same time he turns on the stopwatch, the athlete steps forward towards cone 4. Arriving at cone 4 , the athlete performs gedanbarai block and gyakutsuki punch and a stance with left foot at the front. Then, the athlete steps back to cone 1 and gets ready to perform the movement instructed by testor

g) When the testor provides a sound stimulus with sound 5 at the same time he turns on the stopwatch, the athlete steps sideways towards cone 5. Arriving at cone 5, the athlete performs kekomi kick with right foot, and then step sideways back to cone 1 and gets ready to perform the movement instructed by testor

h) When the testor provides a sound stimulus with sound 6 at the same time he turns on the stopwatch, the athlete steps sideways towards cone 6 . Arriving at cone 6 , the athlete performs kekomi kick with left foot, and then step sideways back to cone 1 and gets ready to perform the movement instructed by testor

i) The testor will stop the test with a whistle when the athlete has completed 6 random moves

j) The finish position is at cone 1 and with initial stance

k) In the event where the athletes fail to perform a move, the athlete should redo the test on his next turn

1) The test is done in 3 repetitions where the best result is taken

m) The athlete is given a break time of 5 minutes after performing 1 test

\subsection{Content Validity}

The analysis using Aiken formula leads to the following results: Item (1) size has fit the karate in kata category with a value of $\mathrm{V} 0.85$; Item (2) distance between cones has fit with a value of $\mathrm{V} 0.80$; Item (3) equipments have fit with a value of $\mathrm{V} 0.80$; Item (4) number of test repetitions has fit with a value of $\mathrm{V} 0.80$; Item (5) test procedure has fit with a value of $\mathrm{V} 0.80$; Item (6) safe instrument has fit with a value of V 0.85 ; Item (7) agility has fit with a value of $\mathrm{V} 0.85$.

Item (8) score taking has fit with a value of $\mathrm{V} 0.80$. The Aiken value of 0.81 to 1.00 indicated that the agreement between the experts was high [26]. This is in line with the literature review which shows that if the coefficient value is more than 0.78 , the test instrument that is made can be categorized as good [27]. Based on data and opinions from the literature, the karate agility test construction in kata category can be said to be good and has high content validity. 
Table 1. The analysis results of Aiken Formula

\begin{tabular}{|c|c|c|c|c|c|c|c|c|c|c|c|c|c|c|c|c|}
\hline \multirow{2}{*}{ Jury } & \multicolumn{2}{|c|}{ Item 1} & \multicolumn{2}{|c|}{ Item 2} & \multicolumn{2}{|c|}{ Item 3} & \multicolumn{2}{|c|}{ Item 4} & \multicolumn{2}{|c|}{ Item 5} & \multicolumn{2}{|c|}{ Item 6} & \multicolumn{2}{|c|}{ Item 7} & \multicolumn{2}{|c|}{ Item 8} \\
\hline & Score & $\mathbf{S}$ & Score & $\mathbf{S}$ & Score & $\mathbf{S}$ & Score & $\mathbf{S}$ & Score & $\mathbf{S}$ & Score & $\mathbf{S}$ & Score & $\mathbf{S}$ & Score & $\mathbf{S}$ \\
\hline A & 4 & 3 & 3 & 2 & 4 & 3 & 4 & 3 & 3 & 2 & 3 & 2 & 4 & 3 & 4 & 3 \\
\hline B & 3 & 2 & 3 & 2 & 4 & 3 & 4 & 3 & 3 & 2 & 3 & 2 & 3 & 2 & 3 & 2 \\
\hline $\mathrm{C}$ & 3 & 2 & 4 & 3 & 3 & 2 & 3 & 2 & 3 & 2 & 4 & 3 & 4 & 3 & 3 & 2 \\
\hline D & 4 & 3 & 4 & 3 & 4 & 3 & 3 & 2 & 4 & 3 & 4 & 3 & 4 & 3 & 4 & 3 \\
\hline E & 4 & 3 & 4 & 3 & 3 & 2 & 3 & 2 & 4 & 3 & 3 & 2 & 3 & 2 & 4 & 3 \\
\hline F & 3 & 2 & 3 & 2 & 3 & 2 & 3 & 2 & 4 & 3 & 3 & 2 & 3 & 2 & 3 & 2 \\
\hline $\mathrm{G}$ & 4 & 3 & 3 & 2 & 3 & 2 & 4 & 3 & 3 & 2 & 3 & 2 & 3 & 2 & 3 & 2 \\
\hline$\sum \mathrm{s}$ & 18 & & 17 & & 17 & & 17 & & 17 & & 17 & & 18 & & 17 & \\
\hline $\mathrm{V}$ & 0.8 & & 0.80 & & 0.80 & & 0.80 & & 0.80 & & 0.80 & & 0.85 & & 0.80 & \\
\hline
\end{tabular}

\subsection{Empirical Validity}

Table 2. Results of Pearson Product Moment Analysis

\begin{tabular}{ccccc}
\hline N & R-table & $\begin{array}{c}\text { R-count } \\
\text { (test 1) }\end{array}$ & $\begin{array}{c}\text { Significance 2 } \\
\text { tailed }\end{array}$ & Status \\
\hline 20 & 0.444 & 0.927 & 0.000 & Valid \\
\hline N & R-table & $\begin{array}{c}\text { R-count } \\
\text { (test 1) }\end{array}$ & $\begin{array}{c}\text { Significance 2 } \\
\text { tailed }\end{array}$ & Status \\
\hline 20 & 0.444 & 0.903 & 0.000 & Valid \\
\hline
\end{tabular}

Based on the empirical validity test of the Pearson moment product, the r-table is $0.444, \mathrm{r}$-count (test 1 ) is 0.927 , r-count (test 2) is 0.903 , significance value is 0.000 . If the r-count is bigger than the r-table and the significance value is $<0.05$, it can be concluded that the result is valid. Thus, the karate agility test instrument in kata category can be said to be valid.

\subsection{Reliability}

Table 3. Cronbach alpha analysis results

\begin{tabular}{cccc}
\hline N & R-table & Cronbach Alpha & Status \\
\hline 20 & 0.444 & 0.802 & Reliable \\
\hline
\end{tabular}

Based on the reliability test using Cronbach alpha, the $\mathrm{r}$-table is 0.444 , Cronbach alpha is 0.802 . If the Cronbach alpha value is greater than the r-table, the result can be said to be reliable. Thus, the instrument of karate agility test in kumite category has high reliability because it has a value of more than 0.7 .

\section{Discussion}

Karate is a sport related to physical contact. The physical aspects of karate are very important. If the athlete has adequate physical condition, the moves performed will be effective and efficient in both attacking and defensive conditions [3]. Agility is one of the physical aspects in karate. Agility is defined as the speed at which the body changes direction after a stimulus is given without failure and loss of balance [28]. The selection of training methods must be tailored to the needs of each sport. Some literature explained that agility-based physical training can improve cognitive function and cardiovascular capability [29].

Kata and kumite in karate have different characteristics of moves. Kumite has the characteristics of fast attacking and defending, while Kata has the characteristics of a steady stance of power and consistency [30]. By knowing the characteristics of each movement, the coach must apply the appropriate approach. Kata athletes have bimotor components of strength and power, while kumite athletes are more dominant in agility [30]. However, based on the authors' observations, agility also plays an important role for kata athletes. For example, agility plays a very important role when the said athlete performs movements forward, sideways and backward by performing techniques. According to literature, agility is a combination of speed, strength and flexibility [31][32]. Therefore, the movement to change direction quickly becomes an important point for kata athletes. This is supported by some literature which states that the movement to change direction quickly is a multi-factor movement that is needed at high intensity which functions to improve motor skills, posture stability, the ability to make decisions quickly and contribute to improving sports performance[33][34][35]. However, there needs to be a test in accordance with the characteristics of the kata category of karate to find out the improvements. A simulated agility test should be prioritized on young athletes in order to improve their skills and motivation [5]. Some literature explained that martial arts and games have different characteristics of agility [34][1]. Several facts explain that the agility training parameters with specific skill movements can improve the athlete's performance better than general skill training [36]. A sport-specific agility test can help determine the athlete's performance. Since agility is an important component in physical fitness, it requires a test that is in accordance with the characteristics of each branch [37]. 
The Aiken analysis used to measure the content validity got the following results: Item (1) size has fit the karate in kata category with a value of V 0.85 ; Item (2) distance between cones has fit with a value of V 0.80 ; Item (3) equipments have fit with a value of V 0.80 ; Item (4) number of test repetitions has fit with a value of $\mathrm{V} 0.80$; Item (5) test procedure has fit with a value of V 0.80 ; Item (6) safe instrument has fit with a value of V 0.85 ; Item (7) agility has fit with a value of $\mathrm{V} 0.85$; Item (8) score taking has fit with a value of $\mathrm{V} 0.80$. The Aiken value of 0.81 to 1.00 indicated that the agreement between the experts was high [26]. Based on data and opinions from the literature, the karate agility test construction in kata category can be said to be good and has high content validity.

Based on the reliability test using Cronbach alpha, the r-table is 0.444 , Cronbach alpha is 0.802. If the Cronbach alpha value is greater than the r-table, the result can be said to be reliable. Thus, the karate agility test instrument in kata category is considered valid. This is in line with the literature review which mentioned that if the coefficient value is more than 0.78 , then the instruments made are considered to be good [27]. From the Cronbach alpha test, the of $r$-table is 0.444 , and the Cronbach alpha is 0.802. If the Cronbach alpha value is greater than r-table, it can be said to be reliable. Thus, the karate agility test instrument in kata category is considered to have high reliability because its value is more than 0.7. This is supported by the literature that it is suggested that the Cronbach alpha value should have a value of 0.60 to 0.71 in order to show stability and have a fairly high agreement. [38][39][40][41]. Therefore, the construction test is considered feasible to measure the karate agility test in kata category. The test developed is an agility test with a combination of techniques in karate because this test is similar to the real match. It is hoped that the creation of this test can be used to measure the agility of kata karate athletes in a special periodization. There were only 20 participants in the empirical validity test. In fact, to conduct a reliability test, the proposed participants amounted to 40 people. However, in implementation, it will be difficult to achieve a homogeneous amount. Thus, this study used a reliability test with fewer participants, namely 20 athletes [42]

\section{Conclusions}

Based on the results of data processing and discussion, the construction of karate agility test in kata category is considered valid and reliable. Thus, the construction of karate agility test in kata category test has been fit and proper to be used to measure the karate agility test in kata category.

\section{Acknowledgements}

The author would like to thank the Forki Sleman karate committee for providing the opportunity to collect data for the writing of this article.

\section{REFERENCES}

[1] K. Mackala et al., "Evaluation of the pre-planned and non-planed agility performance: comparison between individual and team sports," Int. J. Environ. Res. Public Health, vol. 17, no. 3, 2020, doi: 10.3390/ijerph17030975.

[2] J. J. Issn and N. R. Vol, "The Relationship Between Agility and Speed Factors In Sports," vol. 21, no. 9, pp. 66-72, 2021.

[3] D. Yudhistira and Tomoliyus, "Content validity of agility test in karate kumite category," International Journal of Human Movement and Sports Sciences, vol. 8, no. 5, pp. 211-216, 2020, doi: 10.13189/saj.2020.080508.

[4] E. Zemková, "Differential contribution of reaction time and movement velocity to the agility performance reflects sport-specific demands," Hum. Mov., vol. 17, no. 2, pp. 94101, 2016, doi: 10.1515/humo-2016-0013.

[5] E. Zemková and D. Hamar, "Agility performance in athletes of different sport specializations," Acta Gymnica, vol. 44, no. 3, pp. 133-140, 2014, doi: 10.5507/ag.2014.013.

[6] J. Sheppard and W. Young, "Agility literature review: Classifications, training and testing," J. Sports Sci., vol. 24, no. 9, pp. 919-932, 2006, doi: 10.1080/02640410500457109.

[7] R. Styriak, M. Billman, and D. Augustovicova, "Karate agility: The new competition category for children's physical development with very high test/re-test reliability," Ido Mov. Cult., vol. 20, no. 3, pp. 32-37, 2020, doi: 10.14589/ido.20.3.5.

[8] M. Peters, "Karate - Talk in a Canadian Dojo," Journal for undergraduate enhnography, vol. 10, no. 1. pp 20-34, 2020, doi.org/10.15273/jue.v10i1.9946

[9] M. Güler and N. Ramazanoglu, "Evaluation of physiological performance parameters of elite karate-kumite athletes by the simulated karate performance test," Univers. J. Educ. Res., vol. 6, no. 10, pp. 2238-2243, 2018, doi: 10.13189/ujer.2018.061022.

[10] P. A. Piepiora, A. Szmajke, J. Migasiewicz, and K. Witkowski, "The karate culture and aggressiveness in kumite competitors," Ido Mov. Cult., vol. 16, no. 2, pp. 41-47, 2016, doi: 10.14589/ido.16.2.5.

[11] T. Herrera-valenzuela et al., "Relación entre el Movement change in karate position Test con el rendimiento neuromuscular en atletas de karate: Un estudio piloto Relationship between Movement change in karate position Test and neuromuscular performance in karate athletes: A pilot stu," vol. 2041, pp. 505-508, 2021.

[12] C. Doria et al., "Energetics of karate (kata and kumite techniques) in top-level athletes," Eur. J. Appl. Physiol., vol. 107, no. 5, pp. 603-610, 2009, doi: 10.1007/s00421-009-1154-y.

[13] D. Bawiskar and P. Phansopkar, "Efficacy of plyometric training on the agility in police cadets," Indian J. Forensic 
Med. Toxicol., vol. 15, no. 1, pp. 1008-1012, 2021, doi: 10.37506/ijfmt.v15i1.13547.

[14] M. Mitić, M. Paunović, M. Ţivković, N. Stojanović, I. Bojić, and M. Kocić, "Differences in Agility and Explosive Power of Basketball Players in Relation To Their Positions on the Team. / Razlike U Agilnosti I Eksplozivnoj Snazi Ko $\square$ Arka $\square$ a U Odnosu Na Igračke Pozicije U Timu.," Facta Univ. Ser. Phys. Educ. Sport, vol. 16, no. 4, pp. 739-747, 2018.

[15] J. P. Veale, A. J. Pearce, and J. S. Carlson, "Reliability and validity of a reactive agility test for australian football," Int. J. Sports Physiol. Perform., vol. 5, no. 2, pp. 239-248, 2010, doi: 10.1123/ijspp.5.2.239.

[16]Z. Kovacikova and E. Zemková, "The Effect of Agility Training Performed in the Form of Competitive Exercising on Agility Performance," Res. Q. Exerc. Sport, vol. 00, no. 00, pp. 1-8, 2020, doi: 10.1080/02701367.2020.1724862.

[17] M. Tomoliyus, D. Tirtawirya, R. Agus Sudarko, H. Alhafiz Arif, and H. Widodo, "The Contest Validation of Circuit Trainning Design to Improve Biomotor Components in Table Tennis Performance," vol. 278, no. YISHPESS, pp. 336-338, 2019, doi: 10.2991/yishpess-cois-18.2018.83.

[18] F. Noroozi, K. Eisapareh, A. Bahadori, L. Ghahremani, R. Cousins, and H. Mokarami, "Development and validation of dust exposure prevention questionnaire for cardiovascular patients based on the health belief model," BMC Public Health, vol. 20, no. 1, pp. 1-11, 2020, doi: 10.1186/s12889-020-09871-3.

[19] I. Y. Hsu, T. S. Su, C. S. Kao, Y. L. Shu, P. R. Lin, and J. M. Tseng, "Analysis of business safety performance by structural equation models," Saf. Sci., vol. 50, no. 1, pp. 1-11, 2012, doi: 10.1016/j.ssci.2011.04.012.

[20] C. B. Terwee et al., "COSMIN standards and criteria for evaluating the content validity of health - related Patient Reported Outcome Measures: a Delphi study," Qual Life Res, vol. 27, pp. 1159-1170, 2018.

[21] J. W. Creswell, "Reflections on the MMIRA The Future of Mixed Methods Task Force Report," J. Mix. Methods Res., vol. 10, no. 3, pp. 215-219, 2016, doi: $10.1177 / 1558689816650298$.

[22] R. L. Harrison, T. M. Reilly, and J. W. Creswell, "Methodological Rigor in Mixed Methods: An Application in Management Studies," J. Mix. Methods Res., vol. 14, no. 4, pp. 473-495, 2020, doi: 10.1177/1558689819900585.

[23] Sumaryanti, Tomoliyus, and J. Ndayisenga, "Circuit training intervention for adaptive physical activity to improve cardiorespiratory fitness, leg muscle strength static and balance of intellectually disabled children," Sport Mont, vol. 17, no. 3, pp. 97-100, 2019, doi: 10.26773/smj.191019.

[24] A. Wilpers et al., "Modified Delphi Study on Nursing Practice and Science in Fetal Care," JOGNN - J. Obstet. Gynecol. Neonatal Nurs., vol. 50, no. 1, pp. 55-67, 2021, doi: 10.1016/j.jogn.2020.09.158.

[25] lewis. R. Aiken, "Three Coefficients For Analyzing The Reliability And Validity Of Ratings," Educ. Psychol. Meas., vol. 45, pp. 131-141, 1985,

[26] Hendriyadi, "Validity Content: Preliminary Development of
Questionnaire," Journal of Management Research and Business. FE-UNIAT, vol. 2, no. 2, pp. 169-178, 2017.

[27] Yuliarto. H. "Content validity of creativity instrument of playingfootball of sport social school student of real madrid Yogyakarta", In proceeding of international symposium on the transition from school to work, no 144, 2017

[28] J. Arwandi and M. Firdaus, "Effect of Agility Training Towards Soccer Dribbling Skills," vol. 35, no. Icssht 2019, pp. 7-10, 2021, doi: 10.2991/ahsr.k.210130.002.

[29] W. I. B. Loch and K. L. B. Rixius, "T He I Nfluence of R Esistance T Raining on," Training, vol. 22, no. 3, pp. 103$111,2011$.

[30] T. Shalaby, "The Effect Of S. A. Q Training On The Skill Level Of Karate Cadets Thesis by: Taha Ahmed Rashad Shalaby Under Supervision of : Emad Abdel Fattah ELSersy," no. May 2019, pp. 0-6, 2020.

[31] Doni Kurniawan Siti Nurrochmah Febrita Paulina H, "Kemampuan Menggiring Bola Sepak Pada Siswa," pp. 381$397,2016$.

[32] A. Widodo and A. Widodo, "Pengaruh Latihan Ladder Drills icky Shuffle Terhadap Kelincahan," Kesehatan. Olahraga, vol. 05, pp. 40-46, 2016.

[33] M. E. Marjani, S. K. Geok, M. Mojahed, N. S. M. Abdullah, and S. Marjani, "Group Decision Making Approach in Karate Agility Test Selection," 2013, doi: 10.13033/isahp.y2013.044.

[34] D. A. S. Ekulic, A. N. T. E. K. Rolo, M. I. S. Pasic, O. G. U. Ljevic, and M. I. A. P. Eric, “T d n s' ' r -a t,” pp. 3306-3312, 2014.

[35] V. C. de Lima, L. A. A. Castaño, V. V. Boas, and M. C. Uchida, "A training program using an agility ladder for community-dwelling older adults," J. Vis. Exp., vol. 2020, no. 157, pp. 1-7, 2020, doi: 10.3791/60468.

[36] T. Methods and S. Elumalai, "Influences on speed and agility parameters responses to with and without specified skill movement training among league cricket players," vol. 1, no. 1, pp. 24-32, 2021.

[37] Galang Qowiyyuridho , Tomoliyus , Fauzi , "Validity and Reliability of Agility Test with Dribbling and Passing in Soccer Games," International Journal of Human Movement and Sports Sciences, Vol. 9, No. 2, pp. 301 - 307, 2021. DOI: 10.13189/saj.2021.090218

[38] F. Rahimnia and J. F. Hassanzadeh, "The impact of website content dimension and e-trust on e-marketing effectiveness: The case of Iranian commercial saffron corporations," Inf. Manag., vol. 50, no. 5, pp. 240-247, 2013, doi: 10.1016/j.im.2013.04.003.

[39] B. Gallais, C. Gagnon, G. Forgues, I. Côté, and L. Laberge, "Further evidence for the reliability and validity of the Fatigue and Daytime Sleepiness Scale," J. Neurol. Sci., vol. 375, pp. 23-26, 2017, doi: 10.1016/j.jns.2017.01.032.

[40] K. S. Taber, "The Use of Cronbach's Alpha When Developing and Reporting Research Instruments in Science Education," Res. Sci. Educ., vol. 48, no. 6, pp. 1273-1296, 2018, doi: 10.1007/s11165-016-9602-2.

[41] A. Otistovo, "Relationship between logistics service quality, 
customer satisfaction and customer loyalty in courier," Manag. Educ., pp. 3-220, 2017.

[42]F. Larrinaga and R. A. Carrasco, "Virtual connection tree concept application over CDMA based cellular systems," IEE Colloq., vol. 26, no. 32, pp. 217-238, 1997, doi: 10.1049/ic:19970197. 